\title{
Early BDNF Treatment Ameliorates Cell Loss in the Entorhinal Cortex of APP Transgenic Mice
}

\author{
Alan H. Nagahara, ${ }^{1}$ Michael Mateling, ${ }^{1}$ Imre Kovacs, ${ }^{1}$ Ling Wang, ${ }^{1}$ Simone Eggert, ${ }^{1}$ Edward Rockenstein, ${ }^{1}$ \\ Edward H. Koo, ${ }^{1}$ Eliezer Masliah, ${ }^{1}$ and Mark H. Tuszynski ${ }^{1,2}$ \\ ${ }^{1}$ Department of Neurosciences-0626, University of California, San Diego, La Jolla, California 92093, and 2Veterans Affairs Medical Center, San Diego, \\ California 92161
}

Brain-derived neurotrophic factor (BDNF) improves molecular, cellular, and behavioral measures of neural dysfunction in genetic models of Alzheimer's disease (Blurton-Jones et al., 2009; Nagahara et al., 2009). However, BDNF treatment after disease onset has not been reported to improve neuronal survival in these models. We now report prevention of neuronal loss with early life BDNF treatment in mutant mice expressing two amyloid precursor protein (APP) mutations associated with early-onset familial Alzheimer's disease. APP transgenic mice underwent lentiviral BDNF gene delivery into the entorhinal cortices at age 2 months and were examined 5 months later. BDNF-treated mice exhibited significant improvements in hippocampal-dependent contextual fear conditioning compared with controltreated APP mice $(p<0.05)$. Stereological analysis of entorhinal cortical cell number demonstrated $\sim 20 \%$ reductions in neuronal number in layers II-VI of the entorhinal cortex in untreated APP mutant mice compared with wild-type mice $(p<0.0001)$, and significant amelioration of cell loss by BDNF $(p<0.001)$. Moreover, BDNF gene delivery improved synaptophysin immunoreactivity in the entorhinal cortex and, through anterograde BDNF transport, in the hippocampus $(p<0.01)$. Notably, BDNF did not affect amyloid plaque numbers, indicating that direct amyloid reduction is not necessary to achieve significant neuroprotective benefits in mutant amyloid models of Alzheimer's disease.

\section{Introduction}

The entorhinal cortex is a major relay between the hippocampus and cortex and exerts a critical role in learning and memory. The entorhinal cortex exhibits early neuropathology in Alzheimer's disease (AD), contributing to the cardinal $\mathrm{AD}$ symptom of shortterm memory loss (Braak and Braak, 1991; Gomez-Isla et al., 1996; Kordower et al., 2001). Brain-derived neurotrophic factor (BDNF) is a nervous system growth factor that is expressed in multiple cortical regions, including the entorhinal cortex and hippocampus (Altar et al., 1997; Conner et al., 1997). BDNF is actively transported from its sites of production in the entorhinal cortex to the hippocampus and is well known to influence hippocampal synaptic plasticity (Kang and Schuman, 1995; Gooney and Lynch, 2001; Lu, 2003). Moreover, we recently found that BDNF administration to the entorhinal cortex of an amyloid precursor protein (APP) transgenic mouse line (J20), which express two human APP mutations, improves learning and memory, enhances expression of the synaptic protein synaptophysin,

\footnotetext{
Received Nov. 6, 2012; revised July 31, 2013; accepted Aug. 20, 2013.

Author contributions: A.H.N., E.M., and M.H.T. designed research; A.H.N., M.M., I.K., L.W., E.R., and E.M. performed research; S.E. and E.H.K. contributed unpublished reagents/analytic tools; A.H.N., M.M., I.K., L.W., and M.H.T. analyzed data; A.H.N. and M.H.T. wrote the paper.

This work was supported by the National Institutes of Health Grant AG10435, the Veterans Administration, the Alzheimer's Association, the State of California (04-35530), and the Shiley Family Foundation. We thank A. Blesch, J.

Yang, H. Zhang, R. Torres, and A. Hoang for technical assistance; and Lennart Mucke for the J20 mice

The authors declare no competing financial interests.

Correspondence should be addressed to Dr. M.H. Tuszynski, Department of Neurosciences-0626, University of California, San Diego, 9500 Gilman Dr, La Jolla, CA 92093. E-mail: mtuszynski@ucsd.edu.

DOI:10.1523/JNEUROSCI.5195-12.2013

Copyright $\odot 2013$ the authors $\quad 0270-6474 / 13 / 3315596-07 \$ 15.00 / 0$
}

and ameliorates aberrant expression of broad sets of genes that are perturbed as a function of the APP mutation (Nagahara et al., 2009). BDNF administration to the entorhinal cortex also ameliorates age-related neural dysfunction in rodents and primates and prevents the death of cortical neurons after transection lesions of the perforant path (Nagahara et al., 2009). Moreover, BDNF levels decline in AD (Narisawa-Saito et al., 1996; Connor et al., 1997; Hock et al., 2000). Collectively, these findings suggest that BDNF could represent a candidate treatment for AD (Nagahara and Tuszynski, 2011).

However, our previous study in APP transgenic mice failed to demonstrate amelioration of entorhinal cortical neuronal loss when BDNF was administered to mice at age 6 months, after the onset of neurodegeneration, when brains were examined 1.5 months later (Nagahara et al., 2009). The lack of BDNF effect on neuronal loss in the entorhinal cortex may have been attributable to an inability of BDNF to prevent an APP-related mechanism of cell death, or to an insufficient therapeutic time period to detect a beneficial effect; knowledge that BDNF can prevent an APP-related mechanism of neuronal death would strengthen the rationale for its use as a therapy for $\mathrm{AD}$. Accordingly, in the present study, we treated J20 APP transgenic mice with BDNF starting at age 2 months and examined subsequent effects on neuronal survival, synaptic protein, and hippocampaldependent learning at age 7 months. We now report significant effects on BDNF on APP-related mechanisms of cell dysfunction, with no detectable effect on $A \beta$ deposition. These findings both strengthen the rationale for potential BDNF therapy in $\mathrm{AD}$ and indicate that therapeutic benefits can be 
attained in an APP-related disease model without directly modifying $\mathrm{A} \beta$ levels per se.

\section{Materials and Methods}

Experimental design and animal subjects. A total of 57 males and female mice were subjects of this study, including 35 transgenic mice expressing the APP Indiana (V717F) and Swedish (K670M) mutations (J20 strain) on a BI/6 background (Mucke et al., 2000; Palop et al., 2003), and 22 control wild-type (WT) BI/6 mice. A total of 36 mice were used in longterm studies in which lentiviral vectors expressing BDNF or enhanced GFP were injected into the entorhinal cortices at age 2-3 months, as described below; mice then underwent behavioral testing at age 7 months and were killed for anatomical analysis of cell number by stereology, BDNF expression and transport, synaptophysin immunoreactivity, and amyloid plaque number. Twelve APP transgenic mice in this long-term study received injections of lentiviral vectors expressing BDNF, 12 APP transgenic mice received injections of lentiviral vectors expressing the reporter gene GFP, and 12 additional WT mice received either lentiviralGFP (Lenti-GFP; $N=6$ ) or vehicle solution $(N=6)$. Three APP mice that received injections of Lenti-BDNF were eliminated from subsequent analyses because of BDNF mistargeting. An additional 14 mice were used for measures of BDNF levels by ELISA: four APP transgenic mice underwent Lenti-BDNF injections at 2-3 months of age and were assessed 6 weeks later; three APP transgenic mice received injections of Lenti-GFP; four WT mice underwent injections of Lenti-GFP; and three WT mice received injections of vehicle solution into the entorhinal cortex. Finally, four APP transgenic mice and three WT mice underwent stereological assessment of entorhinal cortical neuronal number at age 2-3 months; these mice did not receive intracranial injections.

Lentiviral vector production. Lentiviral vectors genetically modified to secrete human BDNF were prepared as previously described (Nagahara et al., 2009). Briefly, a self-inactivating lentiviral vector (Zufferey et al., 1998) derived from pRRL (Follenzi et al., 2000) was used for virus production. For the constitutive expression of GFP and BDNF, the vector p156sinRRLpptCAG-GFP-PRE (Pfeifer et al., 2002) containing eGFP cDNA was used. For expression of BDNF, the GFP cDNA was replaced by the human BDNF cDNA followed by an internal ribosome entry site and the GFP cDNA. Expression of GFP and BDNF genes, respectively, was driven by the CMV/ $\beta$-actin (CAG) promoter (Niwa et al., 1991).

For lentivirus production, a third-generation lentivirus packaging system was used as previously described (Dull et al., 1998; Blesch, 2004). Viral supernatants were concentrated by ultracentrifugation. Titers were determined by measurement of p24 levels in serial dilutions of vector stock by ELISA (PerkinElmer). Lentivirus was diluted to a concentration of $100 \mu \mathrm{g} / \mathrm{ml}$ for injection. For GFP-expressing virus, infectious units were also determined by infection of 293 cells with serial dilutions of the vector stock and correlated with p24 titers. Virus titers were $100 \mu \mathrm{g} / \mathrm{ml}$ (p24) for the GFP-expressing virus and $100 \mu \mathrm{g} / \mathrm{ml}$ (p24) for the BDNFexpressing virus. Vector was stored at $-80^{\circ} \mathrm{C}$ in Eppendorf tubes until the day of surgery.

Vector injections. Lentiviral vectors expressing BDNF-GFP $(N=12$ animals) or only GFP ( $N=12$ animals $)$ were injected into the entorhinal cortices of J20 mice at age 2 months. WT mice received either Lenti-GFP $(N=6)$ or vehicle solution $(N=6)$. Mice were deeply anesthetized with a ketamine/xylazine mixture under animal protocols approved by the Institutional Animal Care and Use Committee at the University of California, San Diego. A total of $4 \mu \mathrm{l}$ of vector $\left(1.25 \times 10^{8}\right.$ infectious units/ $\mathrm{ml}$ ) was injected into the entorhinal cortices of each hemisphere at a rate of $1 \mu \mathrm{l} / \mathrm{min}$. Bilateral vector injections were made in two sites $(2 \mu \mathrm{l} / \mathrm{site})$ per side of the brain using the following coordinates relative to bregma: anteroposterior -4.7 , mediolateral \pm 2.9 , dorsoventral -3.1 ; anteroposterior -4.8 , mediolateral \pm 3.4 , dorsoventral -2.3 . The scalp was closed with sutures, and the animals recovered on a heating pad. Postoperative deficits were not noted after the gene transfer procedure, and animals were returned to their housing cages.

Fear conditioning task. At age 7 months, mice were tested on a fearconditioning paradigm in Habitest chambers (Coulbourn Instruments). In the conditioning phase of the task, the mouse was place in the chamber and received three $20 \mathrm{~s}$ tones that terminated with a $3 \mathrm{~s}$ footpad shock
(0.45 mA). Twenty-four hours later, each mouse was placed in the same chamber, and freezing was recorded over a 3 min period with no tones (context conditioning). Two hours later, mice were placed in a disguised chamber (new floors, wall covers) and freezing was recorded for a $3 \mathrm{~min}$ period before and during each of three conditioned tone presentation (cue conditioning). Animal movements were tracked with video camera and motion detection software (Coulbourn Instruments).

Histology and stereology. After completion of behavioral testing, mice were killed at 7 months of age and intracardially perfused with cold saline followed by $4 \%$ paraformaldehyde. Brains were sectioned on a microtome set at $30 \mu \mathrm{m}$ thickness. For unbiased stereological analyses, a series of 1-in-12 Nissl-stained sections were examined using StereoInvestigator software (Microbrightfield) on a Ludl motorized system. The anatomic boundaries of the medial entorhinal cortex were determined based on the distinct cytoarchitectonic organization of this region in rodents (Insausti et al., 1997; van Groen, 2001). The medial entorhinal cortex is located on the posterior surface of the cortical mantle bordered medially by presubiculum and parasubiculum, laterally by the lateral entorhinal cortex and perirhinal cortex, ventrally by the ventral surface of the brain, and dorsally by subcortical white matter. Cell quantification was performed separately in layers II, III, and V and VI, based on classic divisions of differing cell density in each cortical lamina and on gross laminar morphology; entorhinal cortex does not have a layer IV cell layer (Insausti et al., 1997; van Groen, 2001). Each layer was outlined at low magnification $(4 \times)$, and cell counts were performed at high magnification $(60 \times)$. A $30 \mu \mathrm{m} \times 30 \mu \mathrm{m}$ counting frame was used within a 100 $\mu \mathrm{m}^{2}$ sampling grid, and cell counts were made within a 8 - to $10-\mu \mathrm{m}$ thick zone that began $5 \%$ below the measured thickness of the section at each site. Only cells with nuclei falling within the sampling zone at each site were counted. Cross-sectional area of the soma at the level of the nucleus was also stereologically measured based on intersection of 6-ray extensions from the cell nucleus. Medial entorhinal cortex layers II, III, and V and VI were outlined, cells were quantified as noted above, and cell body size was measured. One WT subject had incomplete tissue and was not included in the statistical analyses. Findings were compared with unoperated WT $(N=3)$ and APP transgenic $(N=4)$ mice sampled at the start of the study (age 2-3 months).

Quantification of synaptophysin fluorescence was performed in entorhinal cortex, dentate gyrus molecular layer, striatum, and frontal cortex bilaterally using anti-synaptophysin (1:1000; Millipore Bioscience Research Reagents) labeled with a fluorescent secondary antibody (1:250; Invitrogen), as previously reported (Nagahara et al., 2009). Sampled sections consisted of $320 \times 320 \mu \mathrm{m}$ images acquired with an Olympus Confocal Microscope model FV1000-IX81 at $2048 \times 2048$ pixel resolution with a $40 \times$ objective lens. The number of pixels containing synaptophysin immunoreactivity was measured per unit area above a minimum threshold intensity determined in the thresholding function of Image (National Institutes of Health): histograms of pixel brightness reflecting a bimodal distribution of background peak (mode) and a smaller signal peak (synaptophysin-ir), with a 1.5 SD above background (mode) were determined. Synaptophysin data are expressed as percentage of the sampling area occupied by synaptophysin reaction product in each subject.

Quantification of amyloid plaques. In this strain of APP transgenic mice, amyloid plaques are observed in the hippocampus. Tissues were pretreated with $90 \%$ formic acid for $1 \mathrm{~min}$, sections were rinsed, and incubation to block nonspecific labeling was performed in $0.6 \%$ hydrogen peroxidase in TBS with $5 \%$ goat serum and $0.25 \%$ Triton X-100. Sections were then rinsed and incubated overnight in anti-human $\mathrm{A} \beta$ 4 G8 antibody (1:1000; Signet). Sections were then treated sequentially with biotinylated goat anti-mouse secondary antibody (Jackson ImmunoResearch Laboratories), avidin-biotin solution (ABC Elite; Vector Laboratory), and nickel-enhanced diaminobenzidine. Plaques were clearly visible as darkly labeled bodies in the hippocampus and surrounding white matter. The number of $\mathrm{A} \beta$ plaques was quantified in the hippocampus using a series of 1 -in-12 sections per mouse, quantifying all visible plaques per section in each hippocampus. The total number of plaques was counted in the hippocampus for each mouse. There was no significant difference (ANOVA, $F_{(2,32)}=0.98 p=0.38$ ) in the number of 
sampled sections among BDNF-treated transgenic mice $(9.7 \pm 0.5)$, GFP-injected transgenic mice (9.6 \pm 0.6$)$, and WT mice (9.8 \pm 0.3 ), indicating equivalent sampling across groups.

Light-level or fluorescent immunolabeling was performed for BDNF (1:1500; Proteintech Group), GFP (1:1500; Rockland), and $\mathrm{A} \beta$ (4G8; 1:1000; Signet). Secondary antibodies were either fluorescent (1:250; Invitrogen) or light-level avidin/biotin amplification using the ABC Elite kit (1:100; Vector Laboratories) and diaminobenzidine reaction product with nickel chloride intensification.

BDNF ELISA. Six weeks after infusion of lentivirus or vehicle solution into the entorhinal cortex using methods described above, mice were deeply anesthetized and the medial entorhinal cortex region was dissected out and frozen on dry ice. BDNF ELISA used the BDNF DuoSet kit (R\&D System; DY248) following the manufacturer's protocol. Tissue was placed in homogenization buffer $(30 \mu \mathrm{l} / \mathrm{mg}$ tissue weight) and further diluted threefold; $50 \mu \mathrm{l} /$ well was added. Standards were performed in quadruplicates (1-100 pg of hBDNF), and samples were run in triplicates on a single 96well plate. BDNF concentration is expressed in pictograms of BDNF per milligram wet tissue.

Statistics. All behavioral testing and quantification of anatomical sections were performed by observers blinded to group identity. Multiple group differences were tested by ANOVA and post hoc comparisons by Fisher's least square difference, using a significance criterion of $p<0.05$. $t$ tests were used for two group comparisons. Nonparametric tests were performed using Kruskal-Wallis tests, followed by a post hoc Wilcoxon paired comparison. All data are presented as mean \pm SEM, except stereological data, which are presented as $\pm \mathrm{SD}$, by convention.

\section{Results}

On all measures reported below, WT animals that were injected with GFP or vehicle solution did not significantly differ from one another and were combined for subsequent statistical analysis. Specifically, on the fear-conditioning task, the two groups showed similar results on both contextual (vehicle $=38.5 \pm 5.4$ vs Lenti$\left.\mathrm{GFP}=37.1 \pm 7.2 ; t_{(10)}=0.02, p=0.9\right)$ and cued versions of the task $\left(\right.$ vehicle $=63.3 \pm 7.6$ vs Lenti-GFP $=59.7 \pm 7.2 ; t_{(10)}=0.55, p=$ 0.5 ). Results were also similar on stereological analyses (vehicle $=$ $132,245 \pm 1934$ vs Lenti-GFP $=127,890 \pm 5765 ; t_{(10)}=0.51$, $p=0.5$ ), synaptophysin measures (entorhinal cortex, vehicle $=$ $28.4 \pm 1.1$ vs Lenti-GFP $=28.9 \pm 0.8 ; t_{(10)}=0.16, p=0.7$; dentate molecular layer, vehicle $=29.6 \pm 1.6$ vs Lenti-GFP $=26.7 \pm 1.1$; $t_{(10)}=2.2, p=0.2$; frontal cortex, vehicle $=29.7 \pm 1.4$ vs Lenti$\mathrm{GFP}=33.8 \pm 3.8 ; t_{(10)}=0.33, p=0.3$ ) and plaque numbers (absent in both WT groups). Similarly, in our previous study (Nagahara et al., 2009), vehicle-and GPF-treated WT mice did not differ on any measures, suggesting that Lenti-GFP expression does not alter outcomes in WT animals.

Mice were first assessed for effects of BDNF gene expression on hippocampal-dependent learning and memory, using a contextual fear conditioning task (Phillips and LeDoux, 1992). WT mice exhibited contextual learning, with $\sim 40 \%$ of the time spent "freezing" in the operant chamber in anticipation of the paired shock (Fig. 1). APP-GFP mice were significantly impaired on this task, spending only $\sim 15 \%$ of the time freezing (ANOVA, $F_{(2,32)}=4.84$, $p<0.02$; post hoc Fisher's test, $p<0.01$ comparing WT and APPGFP mice; Fig. 1). BDNF-treated APP transgenic mice exhibited

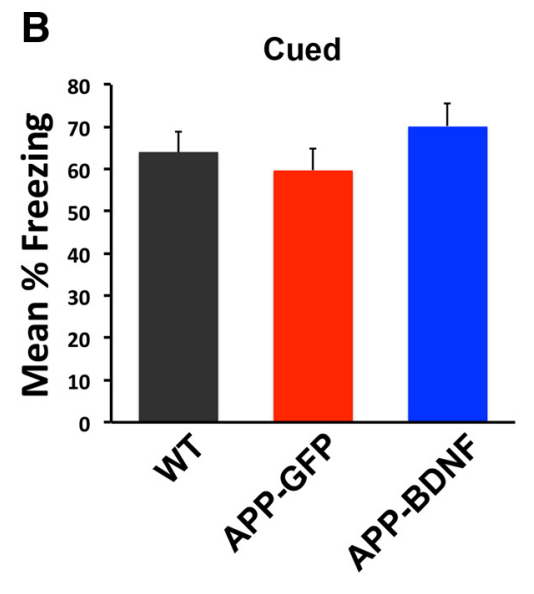

\section{Hippocampal- Dependent}

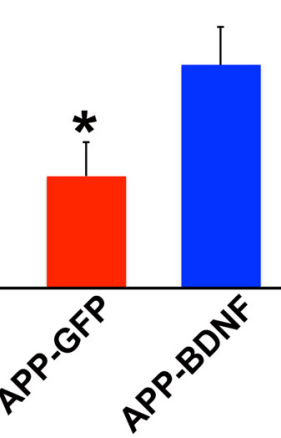

Figure 1. BDNF improves hippocampal-dependent learning. Transgenic mice that receive Lenti-BDNF vector injections into the entorhinal cortex (APP-BDNF) exhibit improvement in a hippocampal-dependent contextual fear conditioning task. $A$, WT exhibit versus WT or APP-BDNF mice. $B, 0$ n a version of the fear-conditioning task that does not depend on hippocampal circuitry, cued fear conditioning, there are no differences between groups (ANOVA, $p=0.4$ ).

significant amelioration of the learning deficit compared with GFPinjected APP transgenic mice (Fig. 1; post hoc Fisher's test, $p<0.05$ ) and did not differ significantly from WT mice ( post hoc Fisher's test, $p=0.5)$. On the cued version of the task, which does not depend on hippocampal circuitry (Phillips and LeDoux, 1992), none of the groups was significantly different $\left(\operatorname{ANOVA}, F_{(2,32)}=0.98, p=\right.$ $0.4)$. Thus, Lenti-BDNF gene delivery significantly and specifically improved a hippocampal-dependent behavioral outcome.

Animals were killed at age 7 months, 5 months after gene delivery. Examination of vector delivery sites showed accurate vector targeting to the entorhinal cortex and persistent gene expression over this time period, evidenced both by GFP expression (Fig. 2A-C) and BDNF immunolabeling (Fig. 2D-F). The targeting, distribution, and extent of vector delivery to the entorhinal cortex did not differ qualitatively among groups. Previous reports indicate that BDNF protein, which is physiologically produced in the entorhinal cortex, undergoes anterograde trafficking to the hippocampus (Altar et al., 1997; Conner et al., 1997). We found that Lenti-BDNF expression in the entorhinal cortex of mice beginning at age 2 months also sustained BDNF transport to the hippocampus over the 5 month period of this experiment, with elevations of BDNF immunolabeling in this region (Fig. 3). The topography of increases in BDNF immunolabeling in the hippocampus corresponded to inputs arising from the entorhinal cortex (Fig. 3D), including the lacunosum moleculare of the CA fields and the outer molecular layers of the dentate gyrus (Fig. 3).

BDNF production in the entorhinal cortex was measured by ELISA after Lenti-BDNF gene delivery (Fig. 4). APP-BDNF transgenic mice showed an approximate 2.3-fold elevation in BDNF levels (Fig. $4 A$; ANOVA, $F_{(3,10)}=11.1, p<0.002$; post hoc Fisher's test, $p<0.005$ APP-BDNF vs other groups; Fig. $4 A$ ). This is a likely underestimation of BDNF expression levels by the vector resulting from dilution of the whole-entorhinal sample by nontransduced tissue.

Stereological analyses were performed on Nissl-stained sections to determine whether neuronal loss occurs in the entorhinal cortex as a function of mutant APP expression. At age 2-3 months, a modest but significant $7.6 \%$ loss of medial entorhinal 


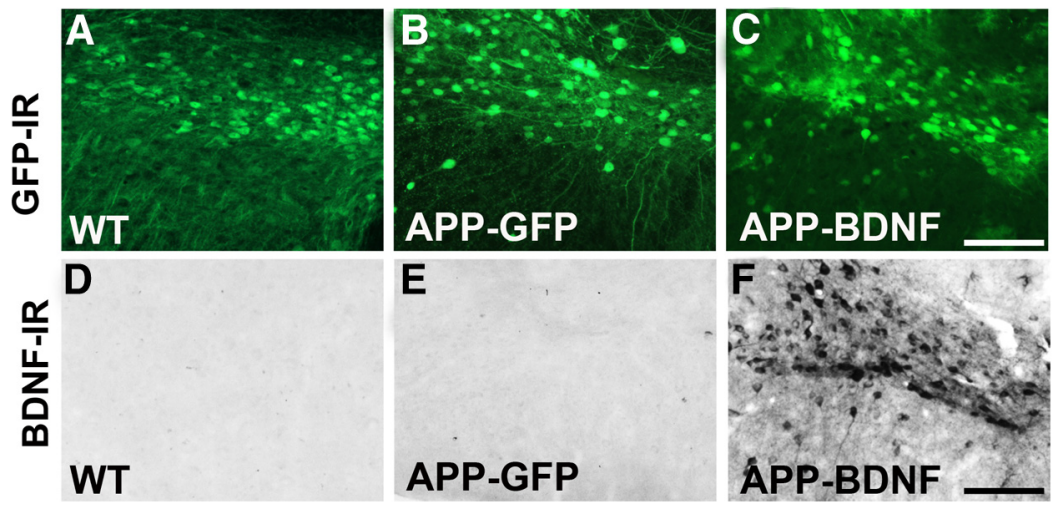

Figure 2. Gene delivery into entorhinal cortex. GFP immunoreactivity shows transduced cells in the entorhinal cortex of $(A)$ WT control mice, $(\boldsymbol{B})$ GFP-treated APP transgenic mice injected with the GFP lentivirus, and (C) BDNF-treated APP transgenic mice injected with a BDNF-GFP lentivirus. BDNF expression is not visible in neurons in the entorhinal cortex of (D) WT or (E) APP-GFP mice, but $(\boldsymbol{F})$ markedly elevated in BDNF-treated APP transgenic mice. Scale bar, $100 \mu \mathrm{m}$.

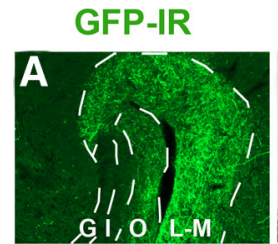

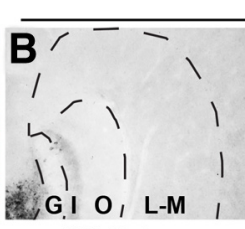

Wild-Type
BDNF-IR

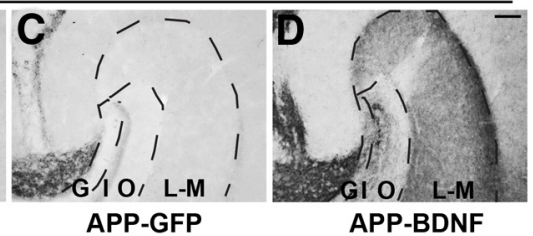

Figure 3. Transport of BDNF protein from entorhinal cortex to hippocampus. A, GFP-labeled axons of entorhinal cortical neurons are detected by GFP immunolabeling in terminal regions of hippocampus, including stratum lacunosum-moleculare (L-M) of $C A$ fields and outer molecular layer (0) layer of dentate gyrus. $\boldsymbol{B}-\boldsymbol{D}, B D N F$ immunoreactivity shows comparable levels of endogenous BDNF levels in (B) WT mice and (C) APP-GFP mice. $\boldsymbol{D}$, In contrast, BDNF levels are markedly elevated in the lacunosummoleculare layer (L-M) and outer molecular layer (0) of the dentate gyrus in APP-BDNF mice. G, Granule cell layer; I, inner molecular layer. Scale bar, $100 \mu \mathrm{m}$.
A

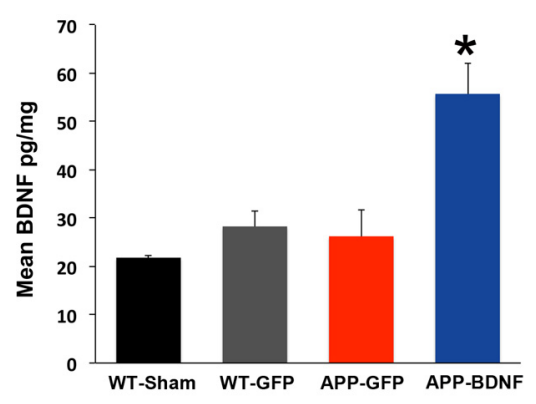

B Standard Curve

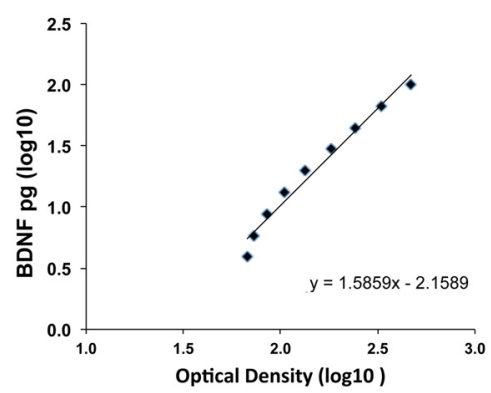

Figure 4. BDNF ELISA. A, Lenti-BDNF gene delivery in APP transgenic mice (APP-BDNF) resulted in significant elevations of BDNF levels compared with APP transgenic mice that received Lenti-GFP (APP-GFP) and WT mice that received Lenti-GFP (WT-GFP) or vehicle control (WT-Sham). ${ }^{*} p<0.01 . B$, Standard curve of known quantities of BDNF.

neurons was detected in APP transgenic mice $\left(t_{(5)}=2.85, p<\right.$ 0.05 ; Table 1). By age 7 months, the amount of entorhinal cortical neuronal loss worsened, with a reduction of $\sim 16.3 \%$ in neuronal number compared with WT mice (ANOVA, $F_{(2,31)}=15.88, p=$ 0.0001 ; post hoc Fisher's test, $p<0.001$ comparing APP-GFP mice with WT controls; Table 1). Notably, BDNF treatment significantly ameliorated entorhinal neuronal loss across all cortical layers in APP transgenic mice compared with APP-GFP mice (post hoc Fisher's test, $p<0.001$; Table 1). Entorhinal cortical neuronal number in the APP-BDNF group significantly exceeded the APP-GFP group in layer II $(p<0.05)$, layer III $(p<0.05)$, and layers V and VI $(p<$ 0.05 ; Table 1$)$. The APP mutation did not result in a reduction in somal size in any entorhinal lamina (data not shown). Thus, APP mutations result in significant reductions in entorhinal neuronal number at age 7 months, and BDNF ameliorates neuronal loss.

We also examined whether BDNF gene delivery influenced the expression of the presynaptic protein synaptophysin after long-term administration. The APP mutation resulted in a significant reduction in synaptophysin labeling in the entorhinal cortex at age 7 months, comparing APP-GFP mice with WT mice (Fig. $5 A, B$; ANOVA, $F_{(2,32)}=15.48, p=0.001$; post hoc Fisher's test, $p<0.001)$. Synaptophsyin labeling was also reduced in the hippocampus in APP-GFP mice compared with WT mice (ANOVA, $F_{(2,32)}=9.24, p<$ 0.01 ; post hoc Fisher's test, $p<0.001)$. APP transgenic mice that received BDNF exhibited significant elevations in synaptophysin levels compared with APP transgenic mice injected with GFP in both the entorhinal cortex and hippocampus (entorhinal cortex, post hoc Fisher's test, $p<0.005$; dentate gyrus, post hoc Fisher's test, $p<0.01$; Fig. 5) and did not differ significantly from WT mice (post hoc Fisher's test: entorhinal cortex, $p=0.8$; dentate gyrus, $p=0.3)$. In the frontal cortex, a region that was not treated with BDNF, both transgenic groups of mice showed significant reductions in synaptophysin labeling compared with WT mice (ANOVA, $F_{(2,32)}=8.67, p=0.001$; post hoc Fisher's test comparing WT with APP-GFP, $p<0.01$; Fisher's test comparing WT with APP-BDNF, $p<0.01$ ), whereas the striatum showed no reduction in synaptophysin immunoreactivity in any group (ANOVA, $F_{(2,32)}=0.84, p=0.4$; Fig. 5).

Next, we determined whether beneficial effects of BDNF treatment on cell number and synaptic markers were associated with concomitant changes in amyloid plaque formation. WT mice exhibited no detectable plaque formation in the hippocampus, whereas both groups of APP transgenic mice exhibited significantly elevated numbers of plaques: KruskalWallis $\chi^{2}(N=33)=21.57, p<0.0001$; post hoc Wilcoxon, $p<0.0001$, APP-GFP and APP-BDNF compared with WT (Fig. 6A,B). The number of amyloid plaques per hippocampus did not differ significantly between the APP-BDNF and APP-GFP groups (post hoc Wilcoxon, $p=0.9$; Fig. $6 B$ ).

There were no significant differences in animal weights at the conclusion of the study: APP-BDNF $=22.0 \pm 0.8 \mathrm{~g}$; APP-GFP $=$ $23.1 \pm 1.0 \mathrm{~g} ; \mathrm{WT}$ GFP $=22.2 \pm 2 \mathrm{~g}$; WT-vehicle injected $21.1 \pm$ $1.0 \mathrm{~g}\left(\mathrm{ANOVA}, F_{(3,10)}=0.55, p=0.7\right)$.

\section{Discussion}

The present study demonstrates that BDNF significantly reduces neuronal loss resulting from mutant APP expression. Further- 
Table 1. Neuronal number in medial entorhinal cortex: stereology ${ }^{a}$

\begin{tabular}{llll}
\hline Age & Layer & WT & APP \\
\hline $2-3$ mo & Total (layer II-VI) & $139,100 \pm 3310$ & $128,455 \pm 5560(-7.6 \%)^{*}$ \\
7.5 mo & Total (layer II-VI) & $130,365 \pm 10,814$ & $109,092 \pm 6529(-16.3 \%)^{*, * *}$ \\
7.5 mo & Layer II & $32,057 \pm 3462$ & $25,109 \pm 3523(-21.9 \%)^{*, * *}$ \\
7.5 mo & Layer III & $46,096 \pm 4654$ & $38,469 \pm 4833(-16.5 \%)^{*, * *}$ \\
7.5 mo & Layer V-VI & $52,211 \pm 5599$ & $45,604 \pm 3856(-12.7 \%)^{*, * *}$ \\
\hline
\end{tabular}

${ }^{a}$ Data are mean \pm SD.

${ }^{*} p<0.05$, APP versus WT.

${ }^{* *} p<0.05$, APP versus APP-BDNF.

more, BDNF gene delivery to the entorhinal cortex results in BDNF trafficking into the hippocampus, circuitry that is important for short-term memory formation, with resultant increases in levels of the presynaptic protein synaptophysin in both entorhinal cortex and hippocampus. Indeed, treated mice exhibit significant improvement in hippocampal-dependent learning.

In an earlier study, we reported that BDNF gene delivery to the entorhinal cortex later in life in APP transgenic mice, after "disease onset," did not prevent neuronal death (Nagahara et al., 2009). The earlier failure may have been the result of either an inability of BDNF to prevent specific APP-related neuronal death mechanisms or the relatively brief duration of treatment (1.5 months), a period of time over which there may have been insufficient progression of cell loss to detect a prosurvival effect; cell degeneration is relatively slow and modest in the APP transgenic mouse model. Yet it is important to determine whether BDNF can prevent APPrelated neuronal death mechanisms to understand the potential of BDNF to advance as a translational therapy for $\mathrm{AD}$. Accordingly, this study began BDNF treatment earlier in life, at 2 months of age when entorhinal neuronal loss is minimal, and extended therapy for another 5 months, a time period over which neuronal loss increased from $6.5 \%$ to $16.3 \%$ in APP-TG mice. Over this time period, BDNF was neuroprotective. Moreover, neuroprotection occurred without detectably altering amyloid plaque formation, indicating that neuronal survival and beneficial cognitive outcomes can be achieved without directly reducing $\mathrm{A} \beta$ plaque levels. Indeed, by targeting a mechanism other than amyloid modulation, the potential exists for future combinations of BDNF and amyloid-modifying therapies.

Together with our previous findings (Nagahara et al., 2009), BDNF treatment: (1) reduces $A \beta$-mediated death in primary neuronal cultures, (2) ameliorates cognitive dysfunction, cell loss, synapse loss, and aberrant gene expression in APPtransgenic mice, (3) reverses age-related cognitive decline and

B
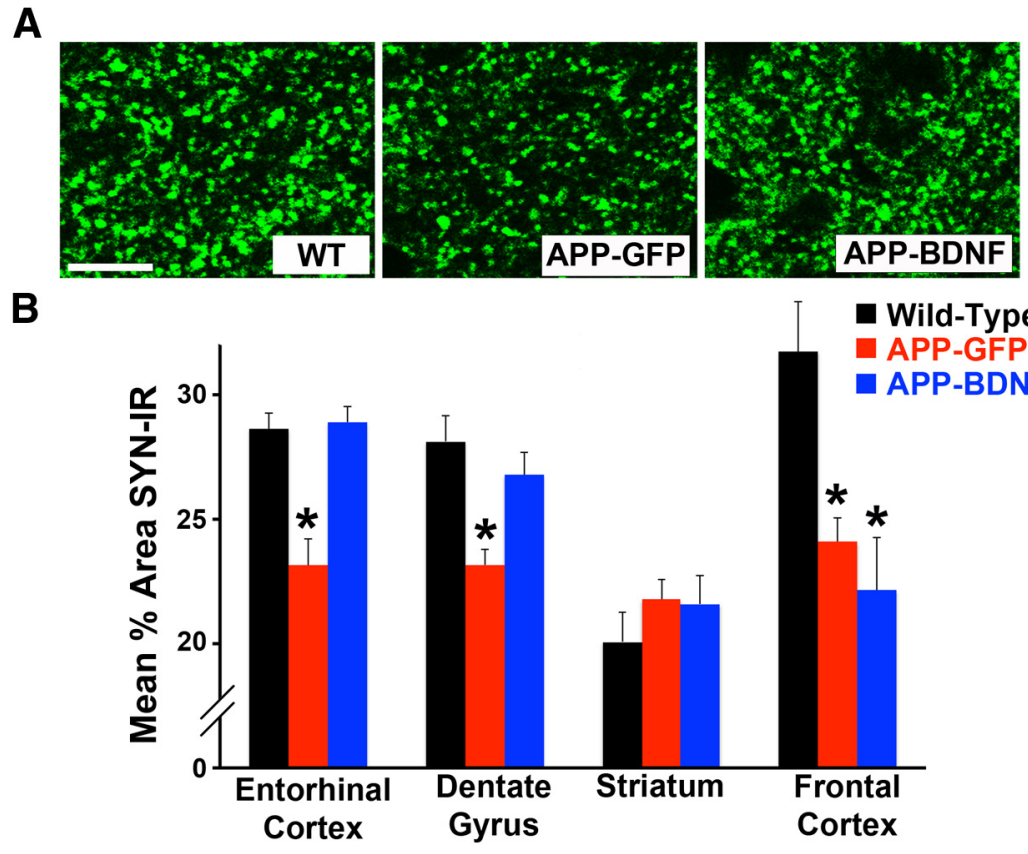

Figure 5. BDNF ameliorates loss of synaptophysin. $\boldsymbol{A}$, Synaptophysin immunolabeling in WT, APP-GFP, and APP-BDNF mice. Labeling is generally less dense and less intense in APP-GFP mice, quantified in $\boldsymbol{B}$. Scale bar, $10 \mu \mathrm{m}$. $\boldsymbol{B}$, Quantification of synaptophysin immunoreactivity reveals uniform reductions in cortical and hippocampal regions, but not striatum, in APP-GFP mice. Notably, cortical regions therapeutically exposed to BDNF, the entorhinal cortex, and hippocampal dentate gyrus showed significant amelioration of reductions in synaptophysin labeling. ${ }^{*} p<0.05$.
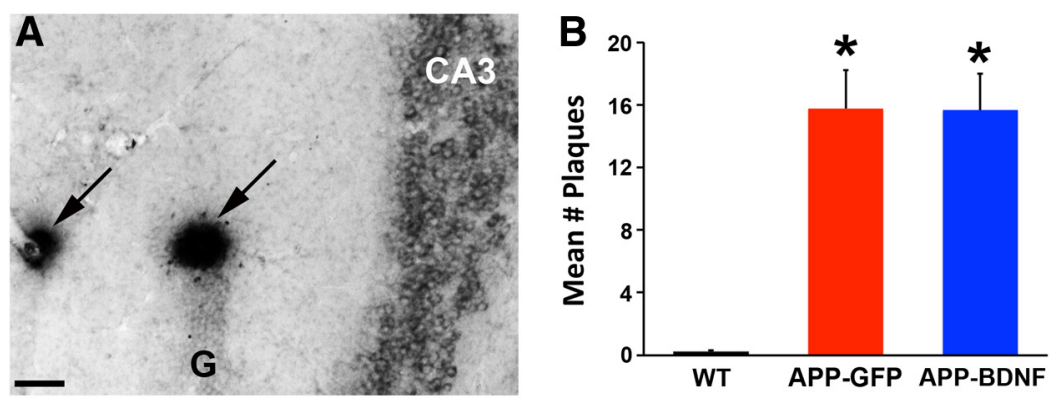

Figure 6. AAV2-BDNF gene delivery does not reduce amyloid plaque formation. $\boldsymbol{A}$, Amyloid plaques in the CA3 region of APP-GFP mice detected with 4G8 antibody. $\boldsymbol{B}$, Quantification reveals an absence of plaques in the brain of WT mice and significant increases in the hippocampus of both APP-GFP and APP-BDNF mice. ${ }^{*} p<0.001$. Scale bar, $100 \mu \mathrm{m}$.

aberrant patterns of gene expression in aged rats, (4) prevents injury-induced cortical neuronal loss in rats, (5) prevents injury-induced neuronal loss in nonhuman primates, and (6) ameliorates cognitive dysfunction and induces neuronal hypertrophy in aged nonhuman primates. Thus, BDNF is a candidate approach for treating slowing neuronal loss and augmenting neuronal function in AD. 
There are important practical considerations in translating growth factor treatments to humans. Growth factors are medium sized, partially polar proteins that do not cross the blood-brain barrier (Barde et al., 1987; Longo and Massa, 2005). Moreover, when injected into the CSF, growth factors fail to extensively penetrate parenchymal target regions (Yan et al., 1994; Kordower et al., 1999) while causing adverse effects from stimulating cell systems adjoining the CSF space, including nociceptors (Saffran and Crutcher, 1990; Winkler et al., 1997), satiety neurons (Williams, 1991), and Schwann cells (Winkler et al., 1997). Another therapeutic challenge is that growth factors need to be administered chronically in neurodegenerative disorders, such as AD.

One means of addressing the need to sustain growth factor delivery to degenerating neural parenchyma over years, while limiting growth factor spread away from targeted regions, is gene therapy. We have shown the safety to date of this delivery method in $\mathrm{AD}$, administering the nerve growth factor gene to cholinergic basal forebrain neurons, a program that is currently in Phase 2 multicenter clinical trials (Tuszynski et al., 2005) (http://clinicaltrials.gov/). Whereas nerve growth factor targets the cholinergic system, which exerts an important neuromodulatory role in cortical excitation, nerve growth factor has no direct effect on cortical neuronal survival. BDNF, in contrast, directly prevents the loss and stimulates the function of cortical and hippocampal neurons in mouse, rat, and nonhuman primate correlative models of AD (Blurton-Jones et al., 2009; Nagahara et al., 2009). Because we cannot disseminate vector distribution throughout the cortex, our work with BDNF specifically targets neural circuitry related to short-term memory function, the cardinal and earliest sign of AD. By expressing BDNF in the entorhinal cortex, we achieve distribution into the hippocampus from natural trafficking pathways. Although neuronal degeneration in other cortical regions might also be preventable with BDNF, a practical and safe means of disseminated cortical delivery of growth factors by gene delivery or other methods (e.g., stem cell migration) (Blurton-Jones et al., 2009) does not yet exist.

Yet there is an important potential benefit in translating BDNF gene delivery to entorhinal-hippocampal circuitry in AD. By targeting treatment to this short-term memory circuitry, we can focus clinical outcome measures on specific features of memory function, allowing clearer determination of potential efficacy than general cognitive measures typically used in AD trials, which suffer from high variability and, potentially, insensitivity (Harrison et al., 2007; Cano et al., 2010). If such a focused clinical trial in $\mathrm{AD}$ showed clear evidence of disease-modifying activity on a memory outcome measure, it would prove the value of growth factor treatment for human neurodegeneration and motivate wider efforts to target diverse cortical systems with growth factors. Moreover, because short-term memory loss is the cardinal symptom of $\mathrm{AD}$ and mild cognitive impairment, effective treatment of this symptom, even in isolation, could result in meaningful improvement in quality of life in afflicted patients. Results of the present study, indicating that BDNF achieves both cell survival and functional stimulation, support the translational path of this research program.

\section{References}

Altar CA, Cai N, Bliven T, Juhasz M, Conner JM, Acheson AL, Lindsay RM, Wiegand SJ (1997) Anterograde transport of brain-derived neurotrophic factor and its role in the brain. Nature 389:856-860. CrossRef Medline

Barde YA, Davies AM, Johnson JE, Lindsay RM, Thoenen H (1987) Brainderived neurotrophic factor. Prog Brain Res 71:185-189. CrossRef Medline
Blesch A (2004) Lentiviral and MLV based retroviral vectors for ex vivo and in vivo gene transfer. Methods 33:164-172. CrossRef Medline

Blurton-Jones M, Kitazawa M, Martinez-Coria H, Castello NA, Müller FJ, Loring JF, Yamasaki TR, Poon WW, Green KN, LaFerla FM (2009) Neural stem cells improve cognition via BDNF in a transgenic model of Alzheimer disease. Proc Natl Acad Sci U S A 106:13594-13599. CrossRef Medline

Braak H, Braak E (1991) Neuropathological stageing of Alzheimer-related changes. Acta Neuropathol 82:239-259. CrossRef Medline

Cano SJ, Posner HB, Moline ML, Hurt SW, Swartz J, Hsu T, Hobart JC (2010) The ADAS-cog in Alzheimer's disease clinical trials: psychometric evaluation of the sum and its parts. J Neurol Neurosurg Psychiatry 81: 1363-1368. CrossRef Medline

Conner JM, Lauterborn JC, Yan Q, Gall CM, Varon S (1997) Distribution of brain-derived neurotrophic factor (BDNF) protein and mRNA in the normal adult rat CNS: evidence for anterograde axonal transport. J Neurosci 17:2295-2313. Medline

Connor B, Young D, Yan Q, Faull RL, Synek B, Dragunow M (1997) Brainderived neurotrophic factor is reduced in Alzheimer's disease. Brain Res 49:71-81. CrossRef Medline

Dull T, Zufferey R, Kelly M, Mandel RJ, Nguyen M, Trono D, Naldini L (1998) A third-generation lentivirus vector with a conditional packaging system. J Virol 72:8463-8471. Medline

Follenzi A, Ailles LE, Bakovic S, Geuna M, Naldini L (2000) Gene transfer by lentiviral vectors is limited by nuclear translocation and rescued by HIV-1 pol sequences. Nat Genet 25:217-222. CrossRef Medline

Gomez-Isla T, Price JL, McKeel DW Jr, Morris JC, Growdon JH, Hyman BT (1996) Profound loss of layer II entorhinal cortex neurons occurs in very mild Alzheimer's disease. J Neurosci 16:4491-4500. Medline

Gooney M, Lynch MA (2001) Long-term potentiation in the dentate gyrus of the rat hippocampus is accompanied by brain-derived neurotrophic factor-induced activation of TrkB. J Neurochem 77:1198-1207. CrossRef Medline

Harrison J, Minassian SL, Jenkins L, Black RS, Koller M, Grundman M (2007) A neuropsychological test battery for use in Alzheimer disease clinical trials. Arch Neurol 64:1323-1329. CrossRef Medline

Hock C, Heese K, Hulette C, Rosenberg C, Otten U (2000) Region-specific neurotrophin imbalances in Alzheimer disease: decreased levels of brainderived neurotrophic factor and increased levels of nerve growth factor in hippocampus and cortical areas. Arch Neurol 57:846-851. CrossRef Medline

Insausti R, Herrero MT, Witter MP (1997) Entorhinal cortex of the rat: cytoarchitectonic subdivisions and the origin and distribution of cortical efferents. Hippocampus 7:146-183. CrossRef Medline

Kang H, Schuman EM (1995) Long-lasting neurotrophin-induced enhancement of synaptic transmission in the adult hippocampus. Science 267:1658-1662. CrossRef Medline

Kordower JH, Palfi S, Chen EY, Ma SY, Sendera T, Cochran EJ, Cochran EJ, Mufson EJ, Penn R, Goetz CG, Comella CD (1999) Clinicopathological findings following intraventricular glial-derived neurotrophic factor treatment in a patient with Parkinson's disease. Ann Neurol 46:419-424. CrossRef Medline

Kordower JH, Chu Y, Stebbins GT, DeKosky ST, Cochran EJ, Bennett D, Mufson EJ (2001) Loss and atrophy of layer II entorhinal cortex neurons in elderly people with mild cognitive impairment. Ann Neurol 49:202213. CrossRef Medline

Longo FM, Massa SM (2005) Neurotrophin receptor-based strategies for Alzheimer's disease. Curr Alz Res 2:167-169. CrossRef Medline

Lu B (2003) BDNF and activity-dependent synaptic modulation. Learn Mem 10:86-98. CrossRef Medline

Mucke L, Masliah E, Yu GQ, Mallory M, Rockenstein EM, Tatsuno G, Hu K, Kholodenko D, Johnson-Wood K, McConlogue L (2000) High-level neuronal expression of $\mathrm{A} \beta$ 1-42 in wild-type human amyloid protein precursor transgenic mice: synaptotoxicity without plaque formation. J Neurosci 20:4050-4058. Medline

Nagahara AH, Tuszynski MH (2011) Potential therapeutic uses of BDNF in neurological and psychiatric disorders. Nat Rev Drug Discov 10:209-219. CrossRef Medline

Nagahara AH, Merrill DA, Coppola G, Tsukada S, Schroeder BE, Shaked GM, Wang L, Blesch A, Kim A, Conner JM, Rockenstein E, Chao MV, Koo EH, Geschwind D, Masliah E, Chiba AA, Tuszynski MH (2009) Neuropro- 
tective effects of brain-derived neurotrophic factor in rodent and primate models of Alzheimer's disease. Nat Med 15:331-337. CrossRef Medline

Narisawa-Saito M, Wakabayashi K, Tsuji S, Takahashi H, Nawa H (1996) Regional specificity of alterations in NGF, BDNF and NT-3 levels in Alzheimer's disease. Neuroreport 7:2925-2928. CrossRef Medline

Niwa H, Yamamura K, Miyazaki J (1991) Efficient selection for highexpression transfectants with a novel eukaryotic vector. Gene 108:193199. CrossRef Medline

Palop JJ, Jones B, Kekonius L, Chin J, Yu GQ, Raber J, Masliah E, Mucke L (2003) Neuronal depletion of calcium-dependent proteins in the dentate gyrus is tightly linked to Alzheimer's disease-related cognitive deficits. Proc Natl Acad Sci U S A 100:9572-9577. CrossRef Medline

Pfeifer A, Ikawa M, Dayn Y, Verma IM (2002) Transgenesis by lentiviral vectors: lack of gene silencing in mammalian embryonic stem cells and preimplantation embryos. Proc Natl Acad Sci U S A 99:2140-2145. CrossRef Medline

Phillips RG, LeDoux JE (1992) Differential contribution of amygdala and hippocampus to cued and contextual fear conditioning. Behav Neurosci 106:274-285. CrossRef Medline

Saffran BN, Crutcher KA (1990) NGF-induced remodeling of mature uninjured axon collaterals. Brain Res 525:11-20. CrossRef Medline

Tuszynski MH, Thal L, Pay M, Salmon DP, U HS, Bakay R, Patel P, Blesch A,
Vahlsing HL, Ho G, Tong G, Potkin SG, Fallon J, Hansen L, Mufson EJ, Kordower JH, Gall C, Conner J (2005) A phase 1 clinical trial of nerve growth factor gene therapy for Alzheimer disease. Nat Med 11:551-555. CrossRef Medline

van Groen T (2001) Entorhinal cortex of the mouse: cytoarchitectonical organization. Hippocampus 11:397-407. CrossRef Medline

Williams LR (1991) Hypophagia is induced by intracerebroventricular administration of nerve growth factor. Exp Neurol 113:31-37. CrossRef Medline

Winkler J, Ramirez GA, Kuhn HG, Peterson DA, Day-Lollini PA, Stewart GR, Tuszynski MH, Gage FH, Thal LJ (1997) Reversible Schwann cell hyperplasia and sprouting of sensory and sympathetic neurites after intraventricular administration of nerve growth factor. Ann Neurol 41:82-93. CrossRef Medline

Yan Q, Matheson C, Sun J, Radeke MJ, Feinstein SC, Miller JA (1994) Distribution of intracerebral ventricularly administered neurotrophins in rat brain and its correlation with Trk receptor expression. Exp Neurol 127: 23-36. CrossRef Medline

Zufferey R, Dull T, Mandel RJ, Bukovsky A, Quiroz D, Naldini L, Trono D (1998) Self-inactivating lentivirus vector for safe and efficient in vivo gene delivery. J Virol 72:9873-9880. Medline 